professionals. Patients want to play an active role in their health care: it is about time we truly listened to them.

\section{Renata Drinkwater,}

Chief Executive, Self Management UK.

E-mail: renata.drinkwaterAselfmanagementuk.org

DOI: 10.3399/bjgp13X673856

\section{PITFALLS OF GPS GETTING BACK DIRECTLY INTO OUT-OF-HOURS CARE}

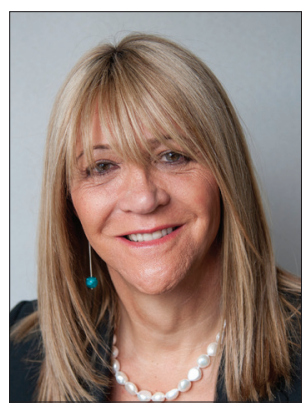

Michelle Drage

Recent ministerial pronouncements and media hyperbole around GPs being personally responsible and even personally providing out-of-hours care have sent shock waves throughout the profession. Such a reversal of an agreement that suited government as recently as 2004, is regarded by three generations of GPs as the last straw. For rural and city GPs alike, that agreement brought an end to constant battle against exhaustion, absence from family and home, marital breakup, neglect, and deterioration of personal health with no respite in sight. Demand for out-of-hours visits could not be stemmed, even by long, open-ended evening surgeries.

There was a terrible knock-on effect on daytime surgery; fatigue, decreased efficiency, irritability, increased risk of clinical error, and defensive practice. Despite our best efforts, patient dissatisfaction and complaints about in-hours and out-of-hours care rose inexorably and in an increasingly riskaverse, performance-driven environment the glue of collegiality and mutual support began to break down.

All of these are as relevant now as they were then, only more so. In-hours days are longer and far more complex than ever before, with consultation time being stretched to the absolute limit with the demands of QOF, the transfer of secondary to primary care, the multimorbidities that accompany longevity and medical advances, as well as ever-rising patient expectations and government targets.

While the GPs of the post-war baby boom era were prepared to both provide and be responsible for out-of-hours care, the GPs of the new baby boom are not. Now equal in numbers, male and female GPs are highly likely to have portfolio careers and less of a tie to life-long job security and satisfaction. They have grown up with different values in terms of work-life balance, shared parental roles, dual incomes, and other societal expectations.

Moreover, they are not trained to take back this archaic role of the clinicallyunnecessary 3 am visit for earache, based on politicians' rose-tinted memories of childhood. Nor are they prepared to take on responsibility for its organisation, in effect becoming the provider of last resort. How would they fit it into the 12-hour days they do already? How would patients receive continuity of care in hours? With doctors no longer living in the communities they serve, what about the journey times? What about the safety risk in our cities, towns, and rural highways? Who would look after the children at night when life partners are often living and working away from home to pursue their careers?

\section{"In-hours days are longer and far more complex}

than ever before, with consultation time being stretched ... with the demands of QOF, the transfer of secondary to primary care, the multimorbidities that accompany longevity ... as well as ever-rising patient expectations and government targets."
Life in New Zealand suddenly looks quite appealing, and if this notion is pursued we can expect many more GPs to pick up their families and go.

\section{Michelle Drage,}

Chief Executive, Londonwide LMCs.

E-mail: Michelle.Dragefalmc.org.uk

DOI: 10.3399/bjgp13X673865

\section{ARGUING FOR MORE GP ENGAGEMENT IN OUT-OF-HOURS CARE}

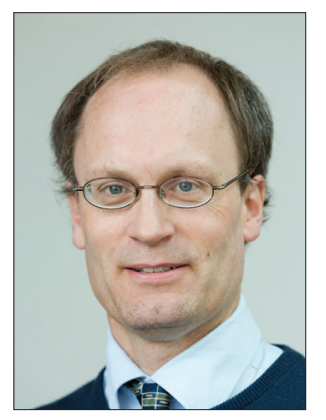

Denys Greenhow

There are three major disconnects causing problems with the quality of out-of-hours care provision loutside funding and staffing levels) that call on GPs to provide leadership. In the long term, GPs working exclusively in out-of-hours care shouldn't be revalidated as GPs unless they demonstrate keeping up to date with chronic disease management. Equally GPs mainly working in hours can be challenged by unscheduled care shifts. An out-of-hours session in is not equivalent to one in hours.

Disconnect two: no coherent clinical governance. Some private companies delivering out-of-hours care are designated bodies with their own responsible officers. However, most require their GPs to be on a performers list which will have its own responsible officer taking priority for their revalidation: why? Within many out-ofhours providers there are no regular peerto-peer meetings to discuss significant events. Confidentiality clauses also stymie transparency. The report by Colin-Thome $\&$ Fields on general practice out-of-hours services in England noted supervision of out-of-hours GPs was mainly through medical directors and indeed urged commissioners to separate discussions on service delivery from quality with providers to maintain focus. The National Out-ofHours Operations Group meets monthly to 